\title{
The Effect of Visualization, Relaxation, and Self-efficacy on the Performance of Men Speed World Record Athletes Category
}

\author{
Ilham*, Dimyati \\ Faculty of Sport Sciences, Yogyakarta State University, Yogyakarta, Indonesia
}

Received November 25, 2020; Revised December 31, 2020; Accepted January 28, 2021

\section{Cite This Paper in the following Citation Styles}

(a): [1] Ilham, Dimyati , "The Effect of Visualization, Relaxation, and Self-efficacy on the Performance of Men Speed World Record Athletes Category," International Journal of Human Movement and Sports Sciences, Vol. 9, No. 1, pp. 48-55, 2021. DOI: 10.13189/saj.2021.090107.

(b): Ilham, Dimyati (2021). The Effect of Visualization, Relaxation, and Self-efficacy on the Performance of Men Speed World Record Athletes Category. International Journal of Human Movement and Sports Sciences, 9(1), 48-55. DOI: 10.13189/saj.2021.090107.

Copyright $\bigcirc 2021$ by authors, all rights reserved. Authors agree that this article remains permanently open access under the terms of the Creative Commons Attribution License 4.0 International License

\begin{abstract}
Background: The speed world record (WR) performance is an achievement made by athletes in the competitive rock-climbing category, where the athlete must complete the climbing route on a standard artificial climbing wall with a height of $15 \mathrm{~m}$ in the shortest possible time. Purpose: This study aims to determine: (1) the effect of visualization and relaxation training on athlete's performance; (2) the effect of self-efficacy on athlete's performance, and (3) the interaction between exercise (visualization, relaxation) and self-efficacy on the performance of rock-climbing athletes in the speed world record category. Design/methodology/approach: This research is experimental research with a true experimental design modified with a factorial design $(2 \times 2)$. The population in this study was all junior and youth WR speed rock climbing athletes, aged between 15-20 years in Yogyakarta and Central Java. A sample of 20 men athletes was taken with the Slovin Formula and ordinal pairing technique. The data were collected using the General Self-efficacy Scale (GSE) to measure self-efficacy and motion climb to measure the performance of rock-climbing athletes with WR speed. A Two-Way ANOVA test was used with the following analysis prerequisites: normality test and homogeneity test. The results of this study showed that: (1) Visualization is better than relaxation; (2) Athletes who have high self-efficacy have better performance than athletes who have low self-efficacy; and (3) There is a significant interaction $(\mathrm{p}<0.05)$ between exercise
\end{abstract}

(visualization and relaxation) and self-efficacy (high and low) on the performance of rock climbing athletes in the WR speed category. Conclusion: The highest performance is obtained with visualization exercises with high self-efficacy; followed by relaxation with high self-efficacy; and visualization exercises with low self-efficacy.

Keywords Performance, Speed World Record, Rock Climbing, Visualization, Relaxation, Self-efficacy

\section{Introduction}

Climbing is a sport that has been popular around the world, namely, as a competitive and recreational sport [1]-[4]. The popularity of rock climbing is going together with many researchers from various countries who have also developed the sport of rock climbing [5]. The popularity of rock climbing has led to increasingly professional competitions.

The World Cup competition is organized regularly by the International Federation of Sport Climbing (IFSC) (IFSC, 2019). The climbing competition that has taken place regularly, of course, demands high climbing performance. This has boosted the performance of researchers, academics, and rock climbing practitioners to 
increase climbing professionalism and success in each climbing category through various studies on improving climbing performance.

Rock climbing-based research has become much more prevalent over the past three decades as a growing global sport. A major trigger that has caught the author's attention is the shift from competitive and recreational sports to the potential inclusion of rock climbing in the calendar of the Tokyo 2020 Olympic Games [6]. Also, the International Rock Climbing Research Association (IRCRA) was created as an institution that brings together coaches and researchers to disseminate their climbing knowledge and collaborate to develop climbing in each discipline or category [7].

Three categories of climbing sports are contested, namely bouldering, lead, and speed (speed climbing: world speed record) [8]. In short, bouldering refers to climbing with a climbing wall height of up to six meters, usually achieved by climbing a predetermined route without using any safety other than a mattress, with a climbing time of 4 minutes.

The speed category (speed world record) takes place on climbing walls as high as $15 \mathrm{~m}$ walls with a standard point along the climbing route (IFSC, 2019). The speed category is part of a competitive climbing sport, requiring competitors to complete the climbing route as quickly as possible on a standard $15 \mathrm{~m}$ high artificial climbing wall. In its development, the speed category does not use the insurer, but the automatic insurer (IFSC, 2019).

Also, several studies on the sport of rock climbing have been carried out to improve climbing performance, for example, analyzed study related to anthropometry [9]-[11]. In addition, several studies related to biomechanics [12][17], physiological [6], [18]-[21], and psychological [18], [22]-[25],

Indonesia is one of the countries which has the potential for performing rock climbing sports shaded by the Indonesian Climbing Federation (FPTI) and has never been absent from organizing or participating in competitions at regional, national, and international levels. Indonesian climbing has also been successful in an Asian and even global level. Of course, these achievements must be well maintained, in particular by carrying out a continuous development program (FPTI, 2019).

Climbing requires special physical aspects and mental skills to improve climbing performance [15]. This means that if you can synergize both physically and mentally, it will improve your climbing performance. The link between physical and psychological through mental visualization exercises can significantly improve climbing performance, that is, it can make climbers more focused and increase training capacity [25]. Therefore, the aspects of physical training and mental training cannot be separated, they must both be trained to achieve the best climbing performance. In addition, aspects of physical training and physical capacity are not sufficient for success in athletic success.
Mental training is necessary in addition to the physical training aspect to achieve consistent performance [9].

Psychophysiological orientation is considered a way of studying actions during exercise to examine physiological processes in the brain and their effects on physical activity. Thus, physical and psychological aspects influence each other fundamentally, ie psychological conditions also affect climbing performance [26]. This reinforces the view that mental training will not be effective without practicing what is trained during mental training [27], [28].

The mental aspects of climbing, especially the speed category, require a more dominant psychological aspect than the lead and bouldering categories. The speed category climbing route has been standardized worldwide, so that each official speed category climbing route for valid matches is the same in terms of point layout, width and climbing length. Compared to other sports, for example athletics with race numbers, the risk of making mistakes is always high during performance.

Unlike the sport of speed WR climbing, tolerance for course errors when climbing can be considered non-existent. Climbers really need to take the climbing route perfectly without mistakes. Therefore, the need for psychological aspects is very important in the speed category of climbing sport, for example, confidence, self-efficacy, risk-taking and the ability to overcome fear of falling while climbing are very important for conditioning. One of the most effective mental exercises for improving climbing performance is a visualization exercise called dissociated visualization.

The disassociated visualization exercise is a form of visualization exercise that can be performed by speed WR climbing athletes, by visualizing the climbing that has been done before. Disassociated visualization is the best visualization model to improve previously poor climbing performance could be better [20]. Because by doing Disassociated Visualization, climbers can replay what was done on the climb that is the cause of the failure in completing the climbing course, without making any significant disappointments or feelings of discontent [20].

Besides, disassociated visualization is useful for improving techniques in the speed category of climbing sport. With programmed dissociated visualization exercises, the climber can correct time-consuming movements, so that effective movements can be obtained to shorten the climb time, i.e. shorter climb times.

Apart from frequent speed training to improve climbing performance, psychological training is also necessary, namely relaxation training. Relaxation training is necessary, as the stress level will increase both before and during the climb where the target speed to stop the climbing time is as short as possible. To avoid possible stress, relaxation training in anticipation of stress is necessary for speed training.

In this case, considering the need for climbing in the WR speed category, progressive relaxation is a solution to 
improve the performance of the athlete. Indeed, progressive relaxation can reduce internal anxiety which generally worsens performance during competition [29]. In rock climbing, the gradual relaxation process can help sharpen awareness of the level of tension in various parts of the climber's body, reduce tension in the body, and relieve tension before climbing performance declines [30].

Therefore, to achieve the perfect movement and achieve the best performance, dissociated visualization and progressive relaxation exercises are needed to involve all five senses. This is an effective psychological training strategy to improve the speed performance of climbing athletes in the speed category. Coupled with training in stressful and competitive situations as a means of anticipating the psychological aspects of competition.

Because of the various issues described above, the authors have been motivated to examine the effect of visualization and relaxation exercises based on confidence level on climbing performance in the world speed record category. This research is related to the psychology of sport and exercise, namely a scientific study of man and his attitudes in exercise and sport and practical applications based on professional principles and guidelines, which can help athletes and bring benefits to sports performance [27], [28], [31]. Thus, the object of this study is visualization and relaxation exercises based on the level of confidence in the performance of climbing athletes in the world speed record category.

\section{Materials and Methods}

This research is an experimental study with a true modified design with a factorial design $(2 \times 2)$, by including control variable [32]-[34]. The study population were all juniors and youth WR speed rock climbing athletes, aged between 15-20 years from Yogyakarta and Central Java. The research sampling were 20 speed climbing athletes taken by slovin formula [35]. Data collection using the General Self-efficacy Scale (GSE) to assess self-efficacy and motion climbing, the speed performance of rock-climbing athletes was evaluated with WR speed. Data were analyzed using Two-way ANOVA after normality test and homogeneity test. Therefore for the purposes of analyzing data, the difference between the pretest and posttest performance of WR speed athletes obtained was converted into a standard score, namely the T-Score. With a higher T-Score, and a short time the better is the performance according to the athlete speed. The good performance was related to the short time made during the exercise.

\section{Procedure}

During the research athletes were classified according to the high self-efficacy and low self-efficacy. The subjects have been given pre-test associated with visualization and progressive relaxation training. The training took 8 weeks with three times per week $(60$ minutes for each meeting). After the training duration the researcher made a posttest to assess if there is any significant improvement about the performance before and after.

Nevertheless, a questionnaire has been addressed to the subjects to assess the high and low self-efficacyand, after getting the result, The content validity, external validity, and reliability analysis quistionaire were conducted. However the instrument used was valided by seven experts: 2 psychology expert lecturers, 2 sports and psychology expert lecturers, and 3 rock climbing national coaches, product moment correlation, and reliability with Cronbach Alpha. Microsft excel and SPSS 25 software were used to obtain the previous result.

Below is Experimental Research Design of Factorial 2 $\mathrm{x} 2$.

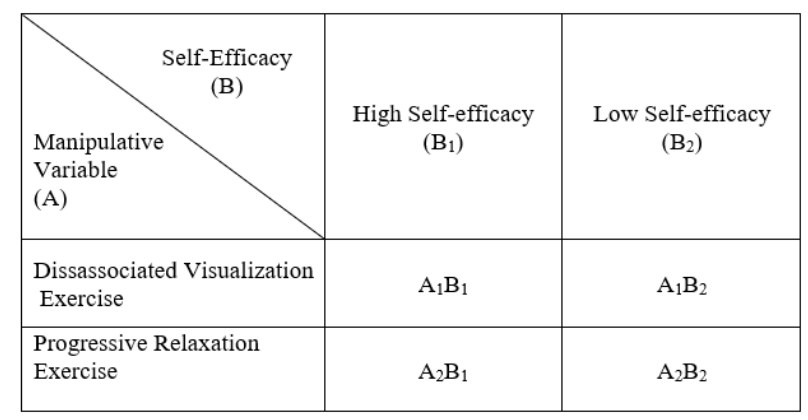

Figure 1. Experimental Research Design of Factorial $2 \times 2$

\section{Legends:}

$\mathrm{A}_{1}$ : Dissassociated visualization

$\mathrm{A}_{2}$ : Progressive relaxation

$\mathrm{B}_{1}$ : High Self-efficacy

$\mathrm{B}_{2}$ : Low Self-efficacy

$A_{1} B_{1}$ : The group of high self-efficacy athletes trained with Dissassociated visualization exercises

$A_{1} B_{2}$ : The group of low self-efficacy athletes trained with disassociated visualization exercises.

$A_{2} B_{1}$ : Athlete's group with high self-efficacy, and trained with progressive relaxation training.

$\mathrm{A}_{2} \mathrm{~B}_{2}$ : Group of athletes with low self-efficacy trained with progressive relaxation training.

\section{Result}

The results of this study showed that: There is a significant difference $(0.003<0.05)$ between visualization and relaxation training on athletes' performance; visualization is better than relaxation; thus, it is proved that $\mathrm{p}$ is less than the specified significance level, namely $5 \%(\mathrm{p}<0.05)$; then the F-statistic was significant from the mean (Post-test, T-Score); Visualization exercise was higher than relaxation exercise $(52.61>47.39$. As seen 
from average performance (post-test); exercise with visualization (7.86 ") was faster than exercise with relaxation $(8.83$ "). This proves that visualization training is better than relaxation training in improving the performance of climbing athletes in the world record speed category.

There is a significant $(p<0.5)$ effect of self-efficacy on rock climbing performance in the WR speed category; athletes who have high self-efficacy have better performance than athletes who have low self-efficacy; There is a significant difference in the performance (post-test) of climbing athletes in the world speed record in terms of self-efficacy, which is indicated by the F-count between B of 128.138 with a p-value of 0.000 ; proven $p$ $<0.05$ by the average $t$ score; high self-efficacy, an average of 58.57 was obtained; whereas at a low self-efficacy, an average of 41.43 has been obtained.

There is a significant interaction $(\mathrm{p}<0.05)$ between exercise (visualization and relaxation) and self-efficacy (high and low) on the performance of rock climbing athletes in the WR speed category. The highest performance is obtained with visualization exercises with high self-efficacy; followed by relaxation with high self-efficacy; and visualization exercises with low self-efficacy.

This indicates that the $\mathrm{F}$ count between $\mathrm{AB}$ (two-way interaction) is 9.782 with a p-value of 0.0006 which is lower than the cut-off of 0.05 . Visual interaction can be described as follows.

1. Bar Chart Comparison of Pre-Test, Post-Test Results, and Improvement (\%) of the Performance of athlete's Speed World Record Athletes.

$\mathrm{A} 1 \mathrm{~B} 1=$ The treatment group of disassociated Visualization Exercise with high Self Efficacy

$\mathrm{A} 1 \mathrm{~B}=$ The treatment group of Disassociated Visualization Exercise with low Self Efficacy

A2B1=The treatment group of Progressive Relaxation exercise with high Self Efficacy

$\mathrm{A} 2 \mathrm{~B}=$ The treatment group of Progressive Relaxation exrcise with low Self Efficacy

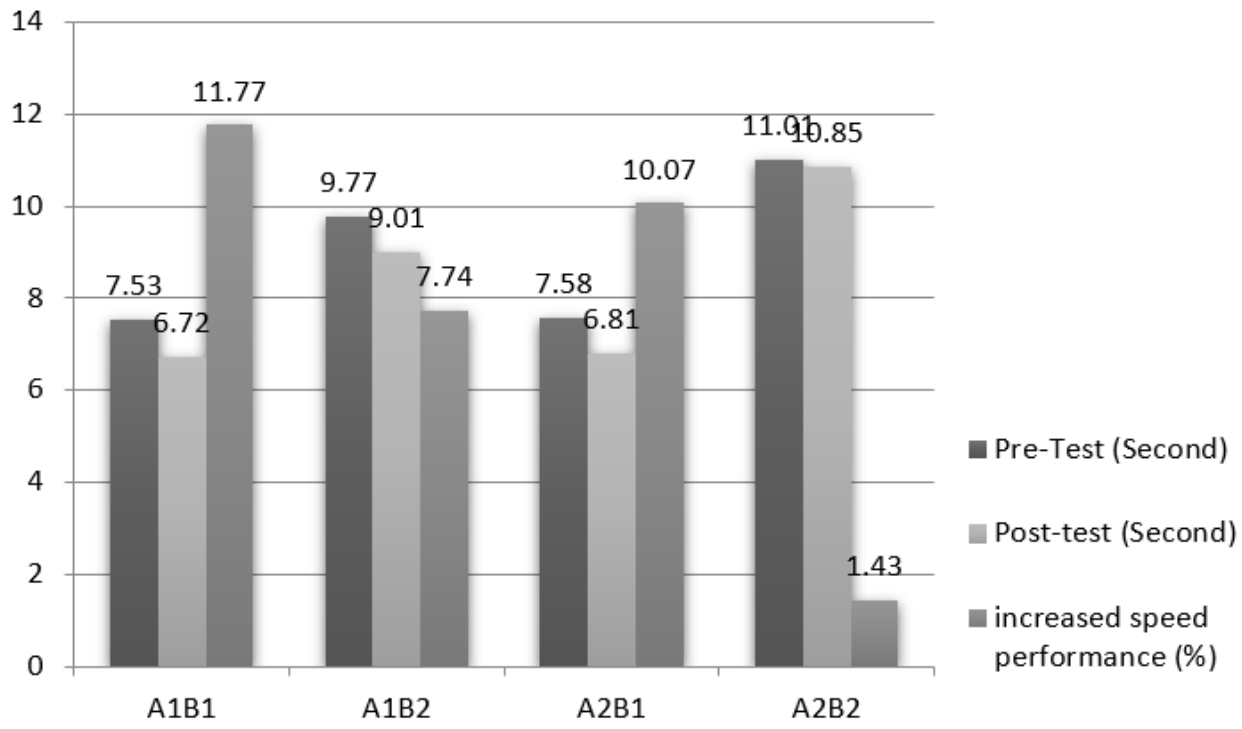

Table 1. The Conclusion Analysis Two-Way Anova of T-Score Performance Post- Test Data

\begin{tabular}{|c|c|c|c|c|c|c|}
\hline \multirow{2}{*}{\multicolumn{2}{|c|}{ Source }} & \multicolumn{5}{|c|}{ Experimental Method } \\
\hline & & Sum of Squares & df & Mean Squares & $\mathbf{F}$ & $\begin{array}{l}\text { Sig. } \\
\text { (p) }\end{array}$ \\
\hline \multirow{3}{*}{ Main Effects } & (Combined) & 1604,782 & 2 & 802,391 & 70,020 & 0,000 \\
\hline & Between A & 136,399 & 1 & 136,399 & 11,903 & 0,003 \\
\hline & Between B & 1468,384 & 1 & 1468,384 & 128,138 & 0,000 \\
\hline \multirow[t]{2}{*}{ 2-Way Interactions } & Inter $\mathrm{AB}$ & 112,101 & 1 & 112,101 & 9,782 & 0,006 \\
\hline & Model & 1716,884 & 3 & 572,295 & 49,941 & 0,000 \\
\hline \multicolumn{2}{|c|}{ Residual } & 183,350 & 16 & 11,459 & -- & -- \\
\hline \multicolumn{2}{|c|}{ Total } & 1900,234 & 19 & 100,012 & -- & -- \\
\hline
\end{tabular}




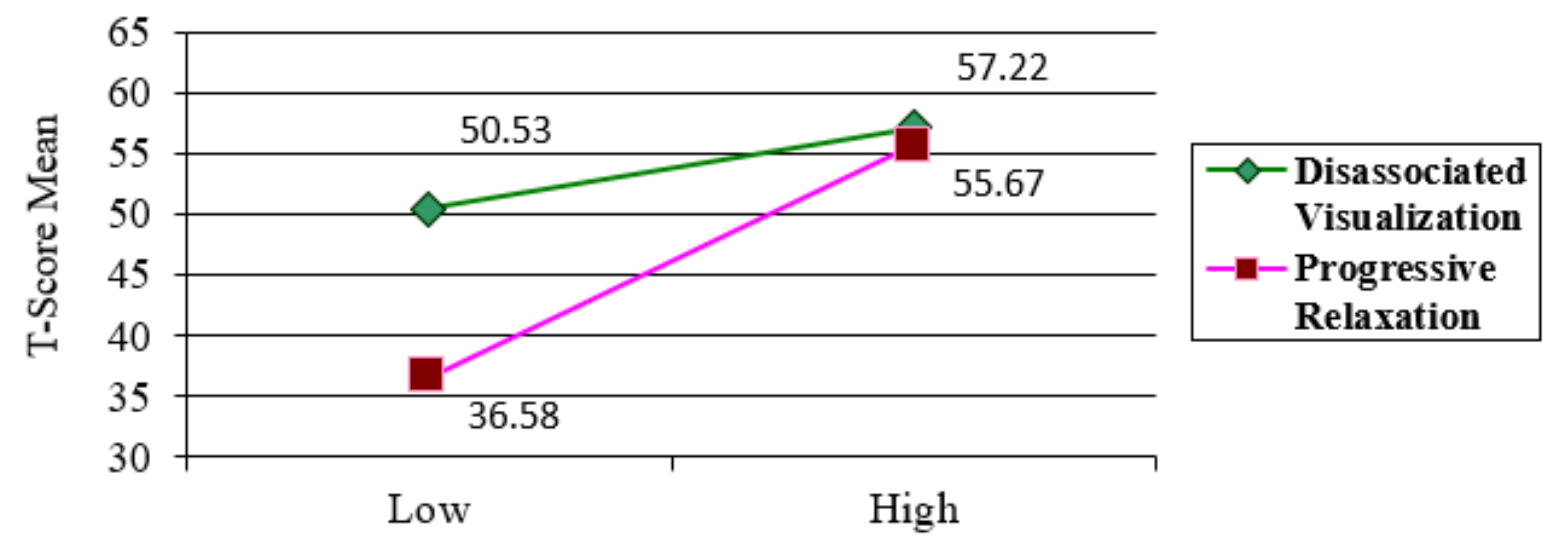

\section{Self-Efficacy}

Figure 2. Interaction of Exercise and Self-Efficacy on Performance (Post-Test) of Climbing Athletes in the Speed World Record category

The results of this study showed that: There is a significant difference $(0.003<0.05)$ between visualization and relaxation training on athletes' performance; visualization is better than relaxation; thus, it is proved that $\mathrm{p}$ is less than the specified significance level, namely $5 \%(\mathrm{p}<0.05)$; then the F-number was significantly from the mean (Post-test T-Score); Visualization exercise was higher than relaxation exercise $(52.61>47.39$. As seen from average performance (post-test); exercise with visualization (7.86 ") was faster than exercise with relaxation ( 8.83 ") This proves that visualization training is better than relaxation training in improving the performance of climbing athletes in the world record speed category.

\section{Discussion}

The increasing popularity of rock climbing has prompted many researchers to investigate the performance of rock climbing. Sport climbing activities dealing with the height and placement of the right body limb [36], if the foot or handrail is placed in the wrong position, it will disperse the mental state [30]. Therefore, visualization aims to improve the movement of thinking earlier than making actual movements. Visualization is also known as imagery, mental rehearsal, meditation. Visualization is the process of creating a mental image of something you choose to do or feel the actual situation.

The form of visualization can be explained in imagining objects, bodies, substances, products, behaviors, actions or other activities that are not visible [37]. Athletes who visualize can relieve anxiety during the competition [27]. When athletes use visualization techniques, not only can they see performance being done, but they can feel the activity going on in their mind [25].

One study conducted and explained that the benefits of psychological aspects in the form of visualization exercises can improve athlete performance, in this case the result showed that there was an increasing of rock climbing athletes performance in the hand of WR speed. Previous researches explained that the physical and mental combination can be improved through visualization exercises [25]. In addition, the presence of systematic visualization exercises increasing athlete's performance, self-efficacy, although this study did not re-test the athlete's self-eficacy after a visualization training program. Visualization exercises, if carried out frequently, can also enhance the athlete's self-efficacy and performance [38].

On the other hand, relaxation exercises help enhance climbing performance (Eklund \&amp; Tenenbaum, 2012). The results of this study contradict previous studies, namely that there used to be no significant effect on enhancing the performance of climbing athletes (Eklund \&amp; Tenenbaum, 2012). The study found significant changes after the introduction of progressive relaxation training, especially for athletes with high self-eficacy.

Therefore, this research finds out about additionally confirmed previous studies related to progressive relaxation, which can improve athletic performance. Indeed, relaxation can decrease internal anxiety which will generally worsen performance during a competition (Lagrange \&amp; Ortiz, 2006). Additionally, relaxation is also mentioned to decrease stress when unexpected occasions happen during competition [27]. Additionally, relaxation can reduce levels of somatic anxiety, even though it was not studied in this study [27], [29], [39], [40].

Disassociated visualization exercises have a greater effect on enhancing the performance of WR speed climbing athletes. Indeed, this visualization workout can enhance the athlete's capability to improve the movement of climbing techniques.

Compared to relaxation exercises, in this study, progressive relaxation exercises were used and considered to be the most effective relaxation exercise for enhancing 
performance, as they have a direct influence on physical work. In rock climbing, progressive relaxation exercise can help sharpen the awareness of the body part, which is very necessary for climbers to gain a fast response to speed climbing in the WR speed category.

Research shows that self-confidence affects an athlete's performance. Those who have high self-confidence will perform better, especially in the sport of rock climbing [38]. This is due to the fact athletes who have high self-efficacy agree within themselves and do their performance if there is something in their route [41].

This is consistent with the dimensions of self-confidence in the form of greatness, strength, generality [38], [41]. Athletes who do whatever to obtain a purpose are based on these three dimensions (Jones et al., 2002).

Self-efficacy has a significant effect on improving the performance of WR speed climbing athletes with a significant value of less than $5 \%(p<0.05)$. The increased performance of world record speed climbing athletes with high self-efficacy is on average $10.42 \%$ higher than that of athletes with low self-efficacy with an average increase of $4.59 \%$. self-efficacy was influenced by its dimensions [38], [42]. This study is also consistent with previous studies related to self-efficacy with high-risk exercise [43] Additionally, previous research has examined the relationship between self-efficacy and habit in indoor and outdoor climbing athletes. This study shows that confident athletes are used to participating in climbing activities which moderate to very difficult trails on both indoor and outdoor venues [44]. The specific area of measuring the specific self-efficacy of speed WR climbing athletes also confirms the validation and reliability of the GSE instrument [45], [46]. This study proved that there is a significant interaction $(\mathrm{p}<0.05)$ between exercise (dissociated visualization and progressive relaxation) and self-efficacy (high and low) on the performance of climbing athletes in the speed WR category. This result was proven by two-way interactions between exercise and self-efficacy on the performance of climbing athletes in the speed world record category which is significant in achieving a $p(s i g)$ value of less than $5 \%(p<0.05)$. It turns out that the results also show that visualization and relaxation exercises are best given to athletes who have high self-efficacy. The group of athletes who were trained using visualization exercises with high and low self-efficacy would experience a more significant effect compared to the group of athletes who were trained using progressive relaxation training with both high and low self-efficacy.

The results showed that the performance of the climbing alter in the speed world record category was highest in the group of dissociated visualization exercises with high self-efficacy; followed by a progressive relaxation group with high self-efficacy; then the dissociated visualization exercise group with low self-efficacy; and finally in the group of progressive relaxation with low self-efficacy. In this study, self-efficacy was proven to determine the performance of climbing athletes with the speed world record. This is related to the dimensions described above, namely that if athletes meet the criteria of these dimensions, they will further accelerate their improved performance, especially in combination with mental training, and will not leave routine training in other aspects. Based on the results of the data analysis and the research findings, it shows that the interactions in each paired group have quite varied interactions.

\section{Conclusions}

The conclusions that can be drawn in this study can be described in several points as follows: There is a significant difference $(p<0.05)$ between dissociated visualization and progressive relaxation exercises on climbing performance in the category of world speed records. Dissociated visualization exercises are better for improving the performance of climbing athletes in the speed world record category compared to progressive relaxation training. There is a significant effect $(p<0.5)$ of self-efficacy on climbing performance in the world record speed category. Athletes who have high self-efficacy perform better than athletes who have low self-efficacy. There is a significant interaction $(p<0.05)$ between exercise (dissociated visualization and progressive relaxation) and self-efficacy (high and low) on the performance of climbing athletes in the world speed record category.

\section{Acknowledgments}

We warmly thank the participants in this research who have given written consent. Also our deeply felt gratitude are addressed to the coaches, and athletes from Daerah Istimewa Yogyakarta and Central Java for the information provided. In addition, The researchers would like to express our gratitude to the Indonesian Ministry of Research and Technology for funding this research

\section{REFERENCES}

[1] K. Y. Woollings et al., "Foot overuse diseases in rock climbing: An epidemiologic study," Sport. Technol., vol. 40 , no. 1, pp. 899-906, 2015, doi: 10.1080/19346182.2015.110 7081 .

[2] E. LoPez-Rivera and J. J. Gonzalez-Badillo, "The effects of two maximum grip strength training methods using the same effort duration and different edge depth on grip endurance in elite climbers," Sport. Technol., vol. 5, no. 3-4, pp. 100-110, 
2012, doi: 10.1080/19346182.2012.716061.

[3] E. López-Rivera and J. J. González-Badillo, "Comparison of the Effects of Three Hangboard Strength and Endurance Training Programs on Grip Endurance in Sport Climbers," $J$. Hum. Kinet., vol. 66, no. 1, pp. 183-193, 2019, doi: 10.2478/hukin-2018-0057.

[4] V. Schöffl, C. Lutter, K. Woollings, and I. Schöffl, "Pediatric and adolescent injury in rock climbing," Res. Sport. Med., vol. 26, no. 1, pp. 91-113, 2018, doi: 10.1080/15438627.2018.1438278.

[5] M. Batuev and L. Robinson, "Organizational evolution and the Olympic Games: the case of sport climbing," Sport Soc., vol. 22 , no. 10 , pp. $1674-1690$, 2019, doi: 10.1080/174304 37.2018.1440998.

[6] K. C. Phillips, J. M. Sassaman, and J. M. Smoliga, "Optimizing rock climbing performance through sport-specific strength and conditioning," Strength Cond. J., vol. 34, no. 3, pp. 1-18, 2012, doi:10.1519/SSC.0b013e318 $255 \mathrm{f} 012$.

[7] N. Draper et al., "Comparative grading scales, statistical analyses, climber descriptors and ability grouping: International Rock Climbing Research Association position statement," Sport. Technol., vol. 8, no. 3-4, pp. 88-94, 2015, doi: 10.1080/19346182.2015.1107081.

[8] L. Seifert, D. Orth, C. Button, and K. Davids, "How expert climbers use perception and action during successful climbing performance," Sci. Climbing Mt., no. January, pp. 181-195, 2016.

[9] C. M. Mermier, J. M. Janot, D. L. Parker, and J. G. Swan, "Physiological and anthropometric determinants of sport climbing performance," Br. J. Sports Med., vol. 34, no. 5, pp. 359-365, 2000, doi: 10.1136/bjsm.34.5.359.

[10] P. B. Watts, L. M. Joubert, A. K. Lish, J. D. Mast, and B. Wilkins, "Anthropometry of young competitive sport rock climbers," Br. J. Sports Med., vol. 37, no. 5, pp. 420-424, 2003, doi: 10.1136/bjsm.37.5.420.

[11] M. F. Novoa-Vignau, O. Salas-Fraire, K. Salas-Longoria, G. Hernández-Suárez, and M. Menchaca-Pérez, "A comparison of anthropometric characteristics and somatotypes in a group of elite climbers, recreational climbers and non-climbers," Med. Univ., vol. 19, no. 75, pp. 69-73, 2017, doi: 10.1016/j.rmu.2017.05.006.

[12] F. Quaine, L. Martin, and J. P. Blanchi, "The effect of body position and number of supports on wall reaction forces in rock climbing," J. Appl. Biomech., vol. 13, no. 1, pp. 14-23, 1997, doi: 10.1123/jab.13.1.14.

[13] M. Ozimek, R. Staszkiewicz, R. Rokowski, and A. Stanula, "Analysis of Tests Evaluating Sport Climbers' Strength and Isometric Endurance," J. Hum. Kinet., vol. 53, no. 1, pp. 249-260, 2016, doi: 10.1515/hukin-2016-0027.

[14] G. Laffaye, J. Collin, G. Levenier, and J. Padulo, "Upper-limb Power Test in Rock-climbing," Int. J. Sports Med., vol. 35, pp. 670-675, 2014.

[15] D. Saul, G. Steinmetz, W. Lehmann, and A. F. Schilling, "Determinants for success in climbing: A systematic review," J. Exerc. Sci. Fit., vol. 17, no. 3, pp. 91-100, 2019, doi: 10.1016/j.jesf.2019.04.002.
[16] R. Staszkiewicz, R. Rokowski, M. L. Michailov, T. Regwelski, and Z. Szyguła, "Biomechanical profile of the muscles of the upper limbs in sport climbers," Polish J. Sport Tour., vol. 25, no. 1, pp. 10-15, 2018, doi: 10.2478/pjst-2018-0002.

[17] I. Schöffl and V. Schöffl, "Epiphyseal stress fractures in the fingers of adolescents: Biomechanics, Pathomechanism, and Risk factors," Eur. J. Sport. Med., vol. 3, no. 1, pp. 27-38, 2016.

[18] T. Dickson, S. Fryer, G. Blackwell, N. Draper, and L. Stoner, "Effect of style of ascent on the psychophysiological demands of rock climbing in elite level climbers," Sport. Technol., vol. 5, no. 3-4, pp. 111-119, 2012, doi: $10.1080 / 19346182.2012 .686504$.

[19] K. LaForge-MacKenzie and P. J. Sullivan, "The relationship between self-efficacy and performance within a continuous educational gymnastics routine," Int. J. Sport Exerc. Psychol., vol. 12, no. 3, pp. 206-217, 2014, doi: 10.1080/1612197X.2014.909511.

[20] J. E. Horst, How to climb series: Learning to climb indoors, 2nd ed. United States of America: Morris Book Publishing, 2012.

[21] P. B. Watts, "Physiology of difficult rock climbing," Eur. J. Appl. Physiol., vol. 91, no. 4, pp. 361-372, 2004, doi: 10.1007/s00421-003-1036-7.

[22] F. Guo, Q. Wang, Y. Liu, and N. J. Hanson, "Changes in blood lactate and muscle activation in elite rock climbers during a 15-m speed climb," Eur. J. Appl. Physiol., vol. 119, no. 3, pp. 791-800, 2019, doi: 10.1007/s00421-018-04070w.

[23] R. MacKenzie et al., "Physical and Physiologic Determinants of Rock Climbing," Int. J. Sports Physiol. Perform., pp. 1-30, 2019, doi: 10.1123/ijspp.2018-0901.

[24] X. Sanchez, M. S. J. Boschker, and D. J. Llewellyn, "Pre-performance psychological states and performance in an elite climbing competition," Scand. J. Med. Sci. Sport., vol. 20, no. 2, pp. 356-363, 2010, doi: 10.1111/j.1600-0838.2009.00904.x.

[25] D. Stanković, A. Raković, A. Joksimović, E. Petković, and D. Joksimović, "Mental Imagery and Visualization in Sport Climbing Training," Act. Phys. Educ. Sport, vol. 1, no. 1, pp. 35-38, 2011, [Online]. Available: http://search.ebscohost.c om/login. aspx?direct $=$ true $\& \mathrm{db}=\mathrm{s} 3 \mathrm{~h} \& \mathrm{AN}=79553341 \&$ lang $=$ zh-tw\&site $=$ ehost-live.

[26] D. Giles et al., "Current understanding in climbing psychophysiology research,” Sport. Technol., vol. 7, no. 34, pp. 108-119, 2014, doi: 10.1080/19346182.2014.968166.

[27] [27] R. H. Cox, Sport Psychology: Concepts and Applications, 7th ed., vol. 14, no. 2. New York: Mc Graw Hill, 2012.

[28] [28] R. S. Weinberg and D. Gould, Foundations of Sport and Exercise Psychology, 6th ed. Miami: Human Kinetics, 2015.

[29] L. Lagrange and J. Ortiz, "Efficacy of Relaxation Techniques in increasing Sport performance in Women Golfers," Sport J., vol. 9, no. 1, pp. 9p-9p, 2006, [Online]. Available: 
http://search.ebscohost.com/login.aspx?direct=true\&AuthT ype $=$ cookie, $i p$, shib\&db=rzh\&AN=106418333\&site=ehost-1 ive.

[30] E. J. Hörst, Training for Climbing: The Defenitive Guide to Improve Your Climbing Performance, 1st ed. Guilford: The Globe Pequot Press, 2003.

[31] R. C. Eklund and G. Tenenbaum, Encyclopedia of Sport and Exercise Psycholology, 2nd ed. Los Angeles: Sage, 2012.

[32] D. S. Borowiak and J. P. D. L. Reyes, "Selection of the best in $2 \times 2$ factorial designs," Commun. Stat., vol. 9, no. 21, pp. 2493-2500, 2007, doi: http://dx.doi.org/10.1080/03610929 208830926.

[33] E. Brunner and M. Denker, "Rank statistics under dependent observations and applications to factorial designs," J. Stat. Plan. Inference, vol. 42, no. 3, pp. 353-378, 1994, doi: 10.1016/0378-3758(94)00002-6.

[34] D. C. Montgomery, Design and Analysis of Experiments, 8th ed., vol. 2. Hoboken: John Wiley \& Sons, Inc, 2013.

[35] J. J. Tejada and J. R. B. Runzalan, "On the misuse of Slovin's formula," Philipp. Stat., vol. 61, no. 1, pp. 129-136, 2012.

[36] D. Heise-flecken and G. Flecken, Rock Climbing: Technique, Equipment, and Safety, 1st ed. Aachen: World Sport Publishers, 2016.

[37] A. Özkan, E. E. Arikan, and E. M. Özkan, "A Study on the Visualization Skills of 6th Grade Students," Univers. J. Educ. Res., no. February, pp. 6-12, 2018, doi: 10.13189/ujer.2018 .060219 .

[38] A. Bandura, Self-Efficacy: The Exercise Control, 1st ed. New York: W. H Freeman and Company, 1997.
[39] J. Fry, "Sport and the anxious mind," J. Philos. Sport, vol. 46, no. 2, pp. 177-190, 2019, doi: 10.1080/00948705.2019.161 0966 .

[40] A. Markati, M. Psychountaki, K. Kingston, K. Karteroliotis, and N. Apostolidis, "Psychological and situational determinants of burnout in adolescent athletes," Int. J. Sport Exerc. Psychol., vol. 17, no. 5, pp. 521-536, 2019, doi: 10.1080/1612197X.2017.1421680.

[41] D. L. Feltz and C. D. Lirgg, "Self-efficacy beliefs of athletes, teams, and coaches," East, vol. 2, no. January 2001, pp. 340 $361,2001$.

[42] M. Karwowski and J. C. Kaufman, The creative self: Effect of beliefs, self-efficacy, mindset, and identity, 1st ed. London: Nikki Levy, 2017.

[43] E. Slanger and K. E. Rudestam, "Motivation and Disinhibition in High Risk Sports: Sensation Seeking and Self-Efficacy," J. Res. Pers., vol. 31, no. 3, pp. 355-374, 1997, doi: 10.1006/jrpe.1997.2193.

[44] V. España-Romero et al., "Physiological responses in rock climbing with repeated ascents over a 10 -week period," Eur. J. Appl. Physiol., vol. 112, no. 3, pp. 821-828, 2012, doi: 10.1007/s00421-011-2022-0.

[45] R. Novrianto, A. K. E. Marettih, and H. Wahyudi, "Validitas Konstruk Instrumen," J. Psikol., vol. 15, no. 1, pp. 1-9, 2019, doi: http://dx.doi.org/10.24014/ jp.v14i2.6943.

[46] U. Scholz, B. Gutiérrez-Doña, S. Sud, and R. Schwarzer, "Is General Self-Efficacy a Universal Construct? Psychometric Findings from 25 Countries Is General Self-Efficacy a Universal Construct? [ 1 ] Urte Scholz; Benicio Gutierrez Dona; Shonali Sud; Ralf Schwarzer," Eur. J. Psychol. Assess., vol. 18, no. 3, pp. 242-251, 2002, doi: $10.1027 / / 1015-5759.18 .3 .242$ 